\title{
Intraoperative Anesthetic Management of the Thoracic Patient
}

\author{
Melina Shoni, MDa, Gerardo Rodriguez, MD ${ }^{\mathrm{b}, *}$
}

\section{KEYWORDS}

- One-lung ventilation complications - Double-lumen endobronchial tube • Bronchial blocker

- Hypoxic pulmonary vasoconstriction - Hypoxemia and one-lung ventilation

\section{KEY POINTS}

- Serious complications from one-lung ventilation include arterial hypoxemia, injury to the nonoperative lung, and right ventricular dysfunction.

- Understanding the effects of anesthetic agents on hypoxic pulmonary vasoconstriction is important for optimizing oxygenation during thoracic surgery.

- Individualized one-lung ventilation management strategies, influenced by the patient's risk for developing hypoxemia, the surgical approach, and the airway device selected, can improve postoperative outcomes.

- Goal-directed fluid therapy and perioperative pain management strategies can reduce morbidity after thoracic surgery.

\section{INTRODUCTION}

The concept of lung isolation dates back to the 1870s when experimental physiologists Edward Pflüger and Claude Bernard introduced the first example of a single-lumen endobronchial cannula. ${ }^{1}$ The transition from single-lumen endobronchial cannulas to double-lumen cannulas that combined short-tracheal and long-bronchial segments in 1889 facilitated many advances in respiratory physiology and independent lung spirometry. ${ }^{1}$ Over the years, these techniques led to a practical progression in human airway instrumentation devices, including two-cuff single-lumen endobronchial tubes (SLTS), double-lumen endobronchial tubes (DLTs), and bronchial blockers (BBs). This specialized armamentarium established the anesthetic practice of one-lung ventilation (OLV) and enabled the performance of complex lung, esophageal, mediastinal, and thoracic wall operations.

\section{ONE-LUNG VENTILATION}

OLV can be defined as the preferential ventilation of the nonoperative lung while deflating the operative lung to achieve an immobile surgical field and to prevent surgical debris, pus, or secretions from entering the contralateral lung (Box 1). The extent of lung deflation differentiates lung separation (adequate deflation) from lung isolation (complete deflation). ${ }^{2}$ In routine practice, OLV is initiated intraoperatively by the anesthesiologist when the surgeon communicates that the pleura is opened; however, there is evidence to support preemptive OLV immediately after lateral positioning for expedited lung collapse. ${ }^{3}$

\section{Double-Lumen Endobronchial Tubes}

The modern version of the DLT stems from a breakthrough invention in 1949 by the Swedish

\footnotetext{
Funding: None.

a Department of Anesthesiology, Boston Medical Center, 750 Albany Street, Power Plant, 2nd Floor, Boston, MA 02118, USA; ${ }^{b}$ Surgical Intensive Care Unit, Department of Anesthesiology, Boston University School of Medicine, Boston Medical Center, 750 Albany Street, Power Plant, 2nd Floor, Boston, MA 02118, USA

* Corresponding author.

E-mail address: gerardo.rodriguez@bmc.org
} 
Box 1

Common indications for one-lung ventilation

Surgical exposure

- Pulmonary resection

- Video-assisted thoracoscopic surgery

- Thoracoscopy

- Lung biopsy

- Lymph node biopsy

- Thoracic aortic surgery

- Esophageal surgery

- Mediastinal surgery

- Thoracic wall surgery

Protective lung isolation

- Malignancy

- Purulent material

- Massive hemoptysis

Differential lung ventilation

- Single-lung transplant

- Bronchopleural fistula

- Bronchial disruption

- Asymmetric parenchymal lung disease

Unilateral bronchial lavage

- Pulmonary alveolar proteinosis

physician Eric Carlens. ${ }^{4} \mathrm{He}$ advanced a red rubber tube with a cuff down to the left main bronchus to seal off the left lung. The tube had a carinal hook to stabilize against the carina. Above the carinal hook was an opening for ventilation of the right main bronchus. Proximal to this was the tracheal cuff. In 1962, Robertshaw ${ }^{5}$ refined Carlen's design by eliminating the carinal hook, widening the D-shaped lumens to lower airflow resistance and facilitate suctioning, and incorporating a flatter extrusion to make it more stable and easier to handle. He designed both left-sided (angle of $45^{\circ}$ at the carina) and right-sided (angle of $20^{\circ}$ at the carina) DLTs.

Today's DLTs are the preferred device for OLV with the longest track record in clinical practice. ${ }^{6}$ The consistent and more convenient design of left DLTs among manufacturers has led to their domination compared with the right DLTs. A DLT that is appropriately sized and placed is key to preventing airway injury and achieving proper lung isolation. The optimal DLT size is considered the largest size that will pass uneventfully through the glottis and trachea and whose bronchial component sits in the mainstem bronchus with only a small air leak. Still, appropriate DLT size selection based on patient factors remains controversial. Chest radiography, ${ }^{7}$ computed tomography, and ultrasonography (US) to measure patient tracheal diameter have been suggested. ${ }^{8}$ Roldi and colleagues ${ }^{9}$ combined patient sex and height with US-derived tracheal measurements to predict DLT size. An undersized DLT can increase the risk of auto positive end-expiratory pressure (PEEP) and dynamic pulmonary hyperinflation, bronchial cuff hyperinflation, failed lung collapse, and possibly tube malposition. ${ }^{10}$ Fiber-optic bronchoscopy remains the gold standard for confirming DLT placement; blindly placed DLTs can be malpositioned up to $48 \%$ of the time. ${ }^{11}$

\section{Bronchial Blockers}

The use of a BB for OLV is increasing worldwide. Various BB types are currently available (Table 1). The specific features of a BB dictate its utilization. Adult sizes are 9 French. Pediatric sizes are 5 French. Table 2 provides a comparison between DLTs and BBs. For most patients, the BB is an appropriate option except for operations involving the main bronchus, distorted bronchial anatomy, or bronchopulmonary lavage. Some advantages of BBs over DLTs include use in patients with difficult airway anatomy where DLT placement may be impossible, patients at high risk for aspiration, patients with tracheostomy, children, surgical procedures with a high risk of left recurrent laryngeal nerve injury, or surgeries requiring postoperative mechanical ventilation. ${ }^{12-14}$ Overall, the rate of major complications from BBs is low. ${ }^{15}$ However, minor airway trauma, failure to achieve lung separation or isolation, balloon malpositioning, device technical malfunctioning (eg, fractured or bent tips, difficult balloon deflation and retrieval, asymmetrical balloon inflation), and inadvertent entrapment of the BB in the surgical staple line have been reported. ${ }^{16,17}$

The debate over which device is best for OLV is still ongoing. ${ }^{18,19}$ For most thoracic procedures, either device can be used safely. The choice is usually based on the specific requirements of each case, patient airway anatomy, and the preference and experience of the anesthesiologist. A recent survey in the United Kingdom among anesthesiologists revealed a $98 \%$ preference rate for DLT use, and $64 \%$ of respondents reported rarely using a BB to provide lung isolation. ${ }^{20}$ Although surgeons seem to also prefer DLTs, studies support similar quality in lung isolation between 


\begin{tabular}{|c|c|}
\hline $\begin{array}{l}\text { Univent Torque Control } \\
\text { (Fuji Systems, Tokyo, Japan) }\end{array}$ & $\begin{array}{l}\text { First manufactured BB; contains a single lumen for } \\
\text { ventilation and a channel that houses the BB; } \\
\text { bulky tube for the size of its ventilating lumen. } \\
\text { Out of favor }\end{array}$ \\
\hline $\begin{array}{l}\text { Cohen Flex-tip (Cook Medical Inc, } \\
\text { Bloomington, IN, USA) }\end{array}$ & $\begin{array}{l}\text { Has a wheel at the operator end that, when turned, } \\
\text { flexes the tip; advancement of the BB is observed } \\
\text { via a fiberscope, which also is passed through a } \\
\text { multiport connector }\end{array}$ \\
\hline $\begin{array}{l}\text { Arndt (Cook Medical Inc, } \\
\text { Bloomington, IN, USA) }\end{array}$ & $\begin{array}{l}\text { Has a lumen through which a wire passes and exits } \\
\text { in a loop, beyond its distal end. The fiberscope is } \\
\text { passed through this loop and is advanced into the } \\
\text { mainstem bronchus with the BB trailing. The wires } \\
\text { nare is loosened and then is removed once the BB } \\
\text { is in place. The position of the BB then is checked } \\
\text { as the fiberscope is withdrawn. Somewhat } \\
\text { cumbersome to use, with multiple steps needed } \\
\text { for proper placement }\end{array}$ \\
\hline $\begin{array}{l}\text { Uniblocker (Fuji Systems, } \\
\text { Tokyo, Japan) }\end{array}$ & $\begin{array}{l}\text { The most newly released, simplest in design and } \\
\text { usage. The BB has a bent tip and comes } \\
\text { preinserted through a multiport connector. It is } \\
\text { simply turned toward the side to be blocked and } \\
\text { advanced under direct vision with the fiber-optic } \\
\text { bronchoscope. Viable option for those with } \\
\text { limited thoracic anesthesia experience, and } \\
\text { placement actually may be easier than a DLT. It is } \\
\text { also significantly less expensive, although more } \\
\text { costly than a DLT }\end{array}$ \\
\hline $\begin{array}{l}\text { Rusch EZ (Teleflex Medical, } \\
\text { Morrisville, NC, USA) }\end{array}$ & $\begin{array}{l}\text { Y-shaped distal end with } 1 \text { blocker for each } \\
\text { bronchus. Similar quality of lung isolation. Can be } \\
\text { placed blindly if a fiberscope is not available or if } \\
\text { visualization proves difficult. Lower incidence of } \\
\text { airway injury than DLT }\end{array}$ \\
\hline
\end{tabular}

DLTs and BBs. ${ }^{13,21}$ Successful utilization of BBs relies on the operator's skill and knowledge of airway anatomy, the device itself, and the fiberscope. ${ }^{13}$ A systematic review and meta-analysis of 39 randomized controlled trials comparing DLTs and BBs for OLV concluded that DLTs were quicker to place and less likely to be positioned incorrectly, but had a higher complication rate. BBs appeared to have a lower incidence of sore throat, hoarseness, and severe airway injury. ${ }^{15,22}$ Thus, for optimal patient care and maintaining technical skills, it is important to develop the skills needed to use both DLTs and BBs.

\section{Two-Cuffed Single-Lumen Endobronchial Tubes}

SLTs are another alternative to DLTs and BBs. They have a single lumen with a distal bronchial cuff and a proximal tracheal cuff and are guided either to the right or to the left mainstem bronchus.
Both lungs can be ventilated when the upper cuff is inflated, and the tip of the tube remains in the trachea. When advanced to one of the main bronchi, OLV of the intubated lung is achieved by keeping the upper cuff deflated and the lower one inflated. Despite the efficient design of the SLT, it has fallen out of favor because of an inability to aspirate secretions from the operative lung, as well as the risk of right upper lobe orifice obstruction during right lung ventilation. ${ }^{2}$

\section{COMPLICATIONS OF ONE-LUNG VENTILATION Hypoxemia}

During OLV, the operative lung is excluded from ventilation while it continues to be perfused. This large ventilation-to-perfusion (V/Q) mismatch creates an obligatory intrapulmonary shunt with resultant hypoxemia defined as oxygen saturation $\left(\mathrm{Spo}_{2}\right)$ less than $90 \%$ or partial pressure of arterial 
Table 2

The advantages and disadvantages of double-lumen endobronchial tube and bronchial blocker

DLT

BB

$+\quad$ Applicable for every thoracic operation

$+\quad$ Only device suitable for bronchopulmonary lavage

Not suitable for thoracic operations that involve the main bronchus (eg, sleeve resection, major bronchopleural fistula, lung transplant, bronchopulmonary lavage, atypical bronchial anatomy)

$+\quad$ Safe, easy, quick, accurate placement $\quad-\quad$ Higher-risk incorrect positioning

$+\quad$ Both lung separation and isolation $\quad+\quad$ Both lung separation and isolation of similar quality with DLTs

$+\quad$ Rapid lung deflation-reinflation as many times as needed (useful in short procedures)

+ Less intraoperative displacement/ repositioning

Longer time to achieve lung separation or isolation

Increased risk of balloon displacement with sequential inflation/deflation of the operated lung or patient position changes

\section{$+\quad$ Suitable for operation in both sides and for sequential surgery to both lungs during the same operation \\ $+\quad$ Allows suctioning of both lungs without interrupting ventilation}

\section{Not recommended}

Limited options for adequate suctioning without interrupting ventilation or contaminating the contralateral lung

\begin{tabular}{|c|c|c|c|}
\hline+ & $\begin{array}{c}\text { Allows bronchoscopy of } \\
\text { non-ventilated lung }\end{array}$ & - & $\begin{array}{l}\text { Inability for visual examination of the } \\
\text { non-ventilated lung }\end{array}$ \\
\hline & $\begin{array}{l}\text { Allows application of CPAP to } \\
\text { non-ventilated lung }\end{array}$ & - & $\begin{array}{l}\text { Difficult application of CPAP to } \\
\text { non-ventilated lung due to smaller } \\
\text { BB lumen }\end{array}$ \\
\hline
\end{tabular}

$+\quad$ Allows differential lung ventilation in ICU

$+\quad$ Inexpensive disposable DLTs

Does not allow differential lung ventilation in ICU

More expensive than disposable DLTs

- Only oral intubation ++ Both nasal and oral intubation

- No available DLT for tracheostomies $++\quad$ Ability to pass through tracheostomies

- Bulky device $\quad+\quad$ Appropriate size to pass via SLT or laryngeal mask airway device

$-\quad$ Inability to selective lobes or segments $\quad+\quad$ Ability to deflate selective lobes or segments

- Difficulties with endobronchial $\quad+\quad$ Easier endobronchial placement
positioning

- Higher risk of airway trauma $\quad+\quad$ Lower risk of airway trauma

- $\quad$ Requires exchange to SLT for patients planned for postoperative ventilation

$+\quad$ Obviates multiple tube exchanges; particularly useful in cases with difficult airway, airway edema, distorted upper and lower airway anatomy, long surgery, need for continued postoperative mechanical ventilation

\begin{tabular}{llll}
\hline- & Higher risk of adverse events & + & Slightly lower risk of adverse events \\
\hline$-\quad \begin{array}{c}\text { Risky tube exchange for patients } \\
\text { already intubated with SLT }\end{array}$ & + & $\begin{array}{c}\text { Safer option for patients already } \\
\text { intubated with SLT }\end{array}$ \\
\hline
\end{tabular}


oxygen $\left(\mathrm{PaO}_{2}\right)$ less than $60 \mathrm{~mm} \mathrm{Hg}$. Furthermore, alveolar derecruitment of the nonoperative lung from general anesthesia and lateral positioning also contributes to arterial hypoxemia. ${ }^{23}$ Wang and colleagues ${ }^{24}$ estimated the shunt fraction after 30 and 60 minutes of OLV to be $35 \%$ and $37 \%$, respectively, with an inverse correlation between $\mathrm{PaO}_{2}$ and $\mathrm{V} / \mathrm{Q}$ mismatch.

In response, hypoxic pulmonary vasoconstriction (HPV) activates and redirects blood flow from poorly ventilated lung regions, operative lung, to well-ventilated lung regions, nonoperative lung, to decrease the intrapulmonary shunt. ${ }^{25}$ Factors that inhibit HPV, such as inhaled anesthetics, hypotension, severe chronic obstructive pulmonary disease (COPD), and use of vasodilators or vasoconstrictors, will divert blood flow to the operative lung and worsen V/Q mismatch and hypoxemia. Factors that improve V/Q matching include lateral decubitus position and moderate COPD with air trapping. The likelihood of a patient developing hypoxemia during OLV is associated with several patient- and surgery-specific risk factors (Table 3). ${ }^{26-29}$

Thanks to improved lung isolation devices, improved positioning techniques, and newer anesthetics, the incidence of hypoxemia during OLV has decreased from $25 \%$ in the 1970 s to $4 \%$ to $10 \%$ today. ${ }^{30}$ Healthy individuals can tolerate hypoxemia during $\mathrm{OLV},{ }^{31}$ and $\mathrm{SaO}_{2}$ as low as $85 \%$ to $90 \%$ may be acceptable. ${ }^{31,32}$ Individuals with coexisting cardiovascular, cerebrovascular, or pulmonary disease, however, are at greater risk for hypoxemia-induced complications, including myocardial depression, atrial fibrillation, pulmonary hypertension, and cognitive dysfunction. ${ }^{33}$

Judicious delivery of oxygen is recommended to maintain adequate oxygenation yet minimize the deleterious effects of hyperoxia, such as inflammation, oxidative stress, alveolar wall thickening, absorption atelectasis, and coronary and peripheral vasoconstriction. ${ }^{34}$

Hypoxemia during OLV can be managed methodically and sequentially. First, the fraction of inspired oxygen $\left(\mathrm{FiO}_{2}\right)$ can be increased to 1.0.
An alveolar recruitment maneuver (ARM), consisting of 10 consecutive breaths at a plateau pressure of $40 \mathrm{~mm} \mathrm{Hg}$, can be tried next. Notably, a preemptive ARM of both lungs before instituting OLV has been shown to decrease alveolar dead space and improve arterial oxygenation. ${ }^{35,36}$ The high plateau pressure associated with an ARM can cause transient hemodynamic derangements and, therefore, should be considered carefully before routine use. ${ }^{37}$

Incremental increases in PEEP to the nonoperative lung to a maximum $20 \mathrm{~cm} \mathrm{H}_{2} \mathrm{O}$ can be attempted to open atelectatic alveoli. ${ }^{35,38,39}$ Careful attention is warranted as PEEP is adjusted. When PEEP causes the end-expiratory pressure to approach the inflection point of the patient's static lung compliance curve, oxygenation is likely to improve. Conversely, if the equilibrium endexpiratory pressure increases beyond the inflection point, oxygenation is likely to deteriorate. ${ }^{40}$ The application of PEEP to the nonoperative lung should be individualized by using a PEEP decrement trial; this can improve oxygenation, ventilation, and lung mechanics compared with a standard increase in PEEP of $5 \mathrm{~cm} \mathrm{H}_{2} \mathrm{O} .{ }^{41}$ Clinical trials examining the effect of individualized perioperative ventilator strategies ${ }^{42}$ as well high versus low PEEP during OLV are ongoing. ${ }^{43}$

Apneic oxygen insufflation or continuous positive airway pressure (CPAP) to the operative lung should be considered to improve oxygenation by passive mechanics. ${ }^{44}$ In the specific cases whereby CPAP may be contraindicated, including video-assisted thoracoscopic surgery, highfrequency jet ventilation to the operative lung has been used to assist with both oxygenation and ventilation, while maintaining an acceptable surgical field of vision. ${ }^{45}$ Recently, differential lung ventilation has been described whereby the operative lung is ventilated with minimal tidal volumes (TV). ${ }^{46}$

If hypoxemia persists, two-lung ventilation should be restored to allow for fiber-optic assessment of the lung isolation device position and the presence of secretions. As a last resort, during

\section{Table 3}

Risk factors for developing hypoxemia during one-lung ventilation can be classified as patient specific and surgery specific

\section{Patient-Specific Risk Factors}

- Normal preoperative spirometry

- Body mass index $>30 \mathrm{~kg} / \mathrm{m}^{2}$

- Low baseline $\mathrm{PaO}_{2}$

- History of lung-reducing operation

\section{Surgery-Specific Risk Factors}

- Large, central lung mass

- Right-sided thoracic surgery

- Surgery performed in the supine position 
open thoracotomy, the surgeon can clamp the pulmonary artery $(\mathrm{PA})$ to the operative lung to reduce the shunt fraction and improve oxygenation.

Less common methods for improving refractory oxygenation involve the pharmacologic manipulation of pulmonary blood flow. Total intravenous anesthesia (TIVA) avoids volatile anesthetics and could theoretically preserve HPV, although significant improvements in hypoxemia have not been reported. ${ }^{47}$ Selective dilation of the pulmonary vessels in ventilated lung regions with inhaled nitric oxide (iNO) ${ }^{48}$ or selective constriction of pulmonary vessels in nonventilated regions with almitrine ${ }^{49-51}$ have produced mixed results. Improved oxygenation has been achieved with small doses of $\mathrm{iNO}^{52}$ in patients with pulmonary hypertension and hypoxemia during OLV. ${ }^{53}$ Inhaled iloprost, a prostacyclin analogue, can also improve oxygenation by selectively vasodilating the pulmonary vascular bed and ameliorating V/Q mismatch. ${ }^{54}$ The continuous infusion of dexmedetomidine has demonstrated clinical benefits by improving oxygenation and lung mechanics in patients with moderate COPD undergoing lung surgery, ${ }^{55}$ which was further supported by a subsequent meta-analysis. ${ }^{56}$

For patients at high risk for developing hypoxemia during OLV, additional monitors can help. Oxygen reverse index is a novel noninvasive continuous monitor of real-time blood oxygenation. Based on multi-wavelength pulse cooximetry, its values correlate strongly with $\mathrm{PaO}_{2}$ and decrease earlier than $\mathrm{Spo}_{2}$, identifying hypoxemia earlier. ${ }^{57-60}$ Cerebral oxygen saturation $\left(\mathrm{Scto}_{2}\right)$ can also be monitored, especially in patients at higher risk for postoperative neurocognitive dysfunction. Studies investigating the role of cerebral oximetry in OLV, however, have had mixed results. ${ }^{61-65}$ Interestingly, greater decreases in $\mathrm{SctO}_{2}$ during OLV were found in patients with good preoperative respiratory function compared with patients with poor respiratory function. Although reasons for this paradoxic finding remain unknown, it is theorized that chronic lung disease may induce an oxygen reserve enhancement in some patients. ${ }^{62}$ More studies are needed to demonstrate the changes in $\mathrm{Scto}_{2}$ during OLV and their association with hypoxemic events measured by $\mathrm{Spo}_{2}$.

\section{Acute Lung Injury}

Acute lung injury (ALI) is characterized by a deleterious cascade of inflammatory and vascular permeability changes within the lung parenchyma that results in diffuse alveolar damage. ${ }^{66}$ There are many factors that can cause postoperative ALI, such as interstitial lung disease, excessive fluid administration, and intraoperative transfusion. ${ }^{67}$

Surgical trauma to the operative lung from mechanical handling and reperfusion injury likely accounts for some lung injury noted after thoracic surgery. Less well recognized, however, are the injurious effects of OLV to the contralateral lung. In fact, OLV-associated ALI in the nonoperative lung is more common and can affect healthy lungs even after brief periods of OLV. ${ }^{68}$ In a meta-analysis, the incidence of postoperative ALI was found to be $4.3 \%$, and associated mortality was $26.5 \% .{ }^{69}$ Contributing factors included intraoperative ventilation strategies characterized by high inspiratory TV defined as greater than $10 \mathrm{~mL} / \mathrm{kg}$ predicted body weight, and high peak inspiratory pressures defined as greater than $28 \mathrm{~cm} \mathrm{H}_{2} \mathrm{O}$, both of which lead to abnormal stretching of the fibroelastic architecture of the lung and produce an inflammatory response. ${ }^{70-72}$

An intraoperative ventilation strategy aimed at maintaining adequate gas exchange while protecting the lungs from inflammation can improve postoperative outcomes. The traditional approach of high TV respirations (10-12 $\mathrm{mL} / \mathrm{kg}$ ) to prevent atelectasis, shunting, and oxygen desaturation during OLV has proven to be harmful. ${ }^{73,74}$ TV of $6 \mathrm{~mL} / \mathrm{kg}$ is an acceptable two-lung ventilation strategy. Halving TV to $3 \mathrm{~mL} / \mathrm{kg}$ during OLV may result in unacceptably low TV and dead space ventilation. An approach that includes low TV (4-6 mL/kg) and high PEEP while achieving mean airway pressures less than $25 \mathrm{~cm} \mathrm{H}_{2} \mathrm{O}$ is proven to reduce volutrauma, barotrauma, and atelectrauma in patients with acute respiratory distress syndrome (ARDS). ${ }^{75,76}$ A meta-analysis comparing low (4$6 \mathrm{~mL} / \mathrm{kg}$ ) versus high (8-12 $\mathrm{mL} / \mathrm{kg}$ ) TV strategies during OLV demonstrated preserved gas exchange, lower incidence of pulmonary infiltration, and lower incidence of ARDS in the low TV group without a significant change in postoperative pulmonary complication rate or hospital length of stay. ${ }^{77}$ Applying this approach to OLV has been recommended, ${ }^{78}$ although some anesthesiologists remain reluctant and continue to use strategies that prioritize reducing peak airway pressures. $^{79}$

Avoiding high peak airway pressures $\left(>25 \mathrm{~cm} \mathrm{H}_{2} \mathrm{O}\right.$ ) to achieve adequate TV is an important consideration. One way to achieve adequate TV with lower peak airway pressures is by using pressure-controlled ventilation (PCV) instead of volume-controlled ventilation (VCV). ${ }^{80} \mathrm{~A}$ meta-analysis reported significantly higher $\mathrm{PaO}_{2} / \mathrm{FiO}_{2}$ ratio and lower peak airway pressure in the PCV group compared with the VCV group; however, no clinical difference was found in $\mathrm{PacO}_{2}$, mean airway 
pressures, and postoperative pulmonary complications. ${ }^{81}$ Overall, the advantages of PCV during OLV include lower peak airway pressures, lower intrapulmonary shunt, and improved oxygenation; however, how these advantages contribute to overall morbidity and mortality remains uncertain.

Excessive driving pressure, calculated as plateau pressure minus PEEP, is considered an independent risk factor for mortality in ARDS. ${ }^{82}$ The benefit of targeting lower driving pressures during ventilation for thoracic surgery has been validated. ${ }^{83}$ Compared with conventional ventilation strategies, targeting lower driving pressures led to fewer postoperative pulmonary complications, including lower rates of pneumonia and ARDS. Although low TV is an important component of lung protective ventilation strategies during OLV, evidence suggests that without adequate PEEP, low VT alone does not prevent postoperative pulmonary complications. ${ }^{84}$ The optimal amount of PEEP that will prevent atelectasis and hypoxia from occurring is still debated. An individualized PEEP strategy that produces the lowest driving pressure may be favored. ${ }^{83}$

Technological advancements in extracorporeal lung assist systems, such as extracorporeal membrane oxygenation (ECMO), have expanded the potential for complex thoracic surgery in patients with insufficient pulmonary reserve and at significant risk of ALI. ${ }^{85}$ ECMO has been used with good outcomes in thoracic surgery cases whereby patient-specific comorbidities or anatomic derangements confer infeasible or insufficient ventilation. It is indicated in cases of severe chest trauma warranting tracheoesophageal fistula repair or esophagectomy and in contralateral lung resection in the setting of previous pneumonectomy, lung transplantation, lung volume reduction surgery, difficult OLV, and difficult airway cases.

\section{Right Ventricular Dysfunction}

Thoracic surgery and OLV present a unique situation whereby the right ventricle (RV) is exposed to sudden changes in preload, afterload, and contractility; the summative effect can quickly escalate from insignificant morphologic changes to nonischemic RV injury, RV dysfunction, and eventual RV failure. ${ }^{86}$ Intraoperative factors that can contribute to RV changes are numerous. V/Q mismatch and resultant hypoxemia and hypercapnia during OLV cause pulmonary vasoconstriction and substantial increases in RV afterload. Mechanical ventilation strategies that promote inflammation will negatively affect RV morphology. The mode of mechanical ventilation chosen intraoperatively can contribute. PCV has been shown to be more protective than VCV. ${ }^{87}$ Thoracic epidural analgesia (TEA), if used for perioperative pain control, can cause loss of vasomotor tone and result in peripheral venous pooling, significantly decreasing RV preload. TEA also inhibits the native positive inotropic response of the RV to acute increases in pulmonary vascular resistance. The degree of RV dysfunction may be more severe in the setting of preexisting RV dysfunction or intraoperative factors, such as extensive thoracic surgery, bleeding, hypervolemia, or tachyarrhythmias. Several strategies exist to mitigate RV strain during OLV (Table 4). ${ }^{86}$

Vasoactive agents can be used to optimize RV function during thoracic surgery. Norepinephrine has been shown to improve RV-PA coupling, cardiac output, and RV performance in acute RV dysfunction with PA hypertension; however, high doses can increase pulmonary vascular resistance beyond systemic vascular resistance and should be avoided. ${ }^{88}$ Vasopressin may be considered superior to norepinephrine because of endothelial nitric oxide stimulation in the pulmonary vascular
Table 4
Intraoperative strategies to protect right ventricular function during thoracic surgery and one-lung ventilation

\section{Ventilation Strategies}
Pressure control ventilation
Low TV (4-6 mL/kg)
Plateau pressure $<25 \mathrm{~cm} \mathrm{H}_{2} \mathrm{O}$
Driving pressure $<18 \mathrm{~cm} \mathrm{H}_{2} \mathrm{O}$
Avoid hypoxemia
Avoid hypercapnia

\section{Hemodynamic Strategies}
Consider transesophageal echocardiography Maintenance of sinus rhythm
GDFT
Optimize RV preload
Decrease RV afterload
Increase RV contractility
TEA
Avoid hypothermia
Avoid acidemia 
tree at low doses (0.01-0.03 U/min), thus causing pulmonary vasodilation, but this effect is lost at higher doses, causing coronary vasoconstriction and significant reduction in RV stroke volume. ${ }^{89}$ RV contractility can be enhanced by positive inotropes, such as epinephrine, or by inodilators, such as dobutamine, milrinone, enoximone, and levosimendan, with or without a peripheral vasoconstrictor. Lung transplantation-related RV dysfunction and pulmonary hypertension can be minimized by iNO and prostacyclin, 2 potent pulmonary vasodilators. ${ }^{90}$

\section{INTRAOPERATIVE ANESTHETIC CONSIDERATIONS Maintenance of Anesthesia}

The pharmacologic choice to maintain general anesthesia has been widely debated. Inhaled anesthetics are known to inhibit HPV, whereas TIVA techniques do not. It has been theorized that TIVA would decrease V/Q mismatch and improve oxygenation, rendering TIVA the anesthetic of choice for OLV. ${ }^{91}$ More recent data suggest that oxygenation during OLV is similar between propofol-based anesthesia and isoflurane..$^{92}$ Therefore, other factors must be considered when choosing an anesthetic. Volatile anesthetics have been shown to attenuate the inflammatory response and protect the glycocalyx of the lung parenchyma, ${ }^{93-96}$ and do not appear to exacerbate hypoxemia. ${ }^{97}$

\section{Fluid Management}

A targeted fluid administration strategy for thoracic surgery is an important aspect of reducing postoperative ALI while minimizing end-organ injury. ${ }^{98}$ Practice has changed since the deleterious effects of liberal fluid administration in pneumonectomy were first documented..$^{99}$ Today, euvolemia is the primary goal of intraoperative fluid management in lung resection and esophagectomy surgery. Attaining this goal entails navigating the balance between extreme ends of the fluid therapy spectrum to achieve an ideal lung water state.

Excessive fluid administration in lung resection can cause postoperative pulmonary edema, ARDS, reintubation, and pneumonia. ${ }^{99-101}$ In esophagectomy, ARDS, pneumonia, prolonged intensive care unit (ICU) stays, ${ }^{102}$ and increased morbidity ${ }^{103}$ and mortality ${ }^{104}$ correlate with fluid overload strategies.

Fluid restrictive strategies during major surgery are associated with a significant risk of perioperative acute kidney injury (AKI). ${ }^{105}$ Colloid solutions that maximize the capillary oncotic load and minimize interstitial edema can inadvertently cause
AKI. ${ }^{106,107} \mathrm{AKI}$ in both lung resection and esophagectomy is associated with greater morbidity. ${ }^{107}$

Ideal fluid management strategies remain controversial. The use of dynamic hemodynamic parameters to target fluid administration, called goal-directed fluid therapy (GDFT), has been adopted by fast-track surgery experts in elective lung surgery. GDFT is now a cornerstone of most perioperative strategies to expedite patient recovery while minimizing postoperative complications. ${ }^{108}$ GDFT strategies driven by objective data, such as pulse pressure variation and stroke volume variation, are gaining favor, although some strategies rely on the relationship between heart and lung interactions and are not as reliable in open thoracotomy. ${ }^{109}$

\section{Pain Management}

Multimodal pain management strategies aim to provide adequate postoperative analgesia while reducing the reliance on opioids. In addition to oral and intravenous nonopioids, regional anesthesia is commonplace. TEA is the gold standard for controlling postoperative pain and a foundation of accelerated recovery pathways in thoracic surgery. ${ }^{110}$ In routinely used doses, TEA does not significantly affect oxygenation and might prevent the development of ALI and associated postoperative pulmonary complications. ${ }^{111}$ Alternative regional anesthesia techniques, such as paravertebral block, erector spinae block, and serratus anterior block, can provide adequate postoperative pain relief with less systemic hypotension, but require additional specialized training and may have limited efficacy. ${ }^{112}$

\section{SUMMARY}

Preoperative assessment and risk-stratification of the prospective thoracic surgery patient, including the risk of developing hypoxemia during OLV, are crucial in formulating an appropriate intraoperative anesthetic plan. Hypoxemia, ALI, and right ventricular dysfunction are significant complications of OLV. Anesthesiologists should be prepared to navigate these problems and methodically choose a patient-specific management plan that mitigates perioperative morbidity. Ventilator management strategy, GDFT, and perioperative pain control are important components for optimizing postoperative recovery after thoracic surgery.

\section{DISCLOSURE}

The authors have nothing to disclose. 


\section{REFERENCES}

1. McGrath B, Tennuci C, Lee G. The history of onelung anesthesia and the double-lumen tube. $J$ Anesth Hist 2017;3(3):76-86.

2. Falzon D, Alston RP, Coley $\mathrm{E}$, et al. Lung isolation for thoracic surgery: from inception to evidencebased. J Cardiothorac Vasc Anesth 2017;31(2): 678-93.

3. Zhang Y, Yan W, Fan Z, et al. Preemptive one lung ventilation enhances lung collapse during thoracoscopic surgery: a randomized controlled trial. Thorac Cancer 2019;10(6):1448-52.

4. Carlens E. A new flexible double-lumen catheter for bronchospirometry. J Thorac Surg 1949;18(5): 742-6.

5. Robertshaw FL. Low resistance double-lumen endobronchial tubes. Br J Anaesth 1962;34:576-9.

6. Brodsky JB, Lemmens HJ. Left double-lumen tubes: clinical experience with 1,170 patients. J Cardiothorac Vasc Anesth 2003;17(3):289-98.

7. Brodsky JB, Macario A, Mark JB. Tracheal diameter predicts double-lumen tube size: a method for selecting left double-lumen tubes. Anesth Analg 1996;82(4):861-4.

8. Sustic A, Miletic D, Protic A, et al. Can ultrasound be useful for predicting the size of a left doublelumen bronchial tube? Tracheal width as measured by ultrasonography versus computed tomography. J Clin Anesth 2008;20(4):247-52.

9. Roldi E, Inghileri P, Dransart-Raye O, et al. Use of tracheal ultrasound combined with clinical parameters to select left double-lumen tube size: a prospective observational study. Eur J Anaesthesiol 2019;36(3):215-20.

10. Lohser J, Brodsky JB. Undersizing left doublelumen tubes. Anesth Analg 2008;107(1):342.

11. Sustic A, Protic A, Cicvaric T, et al. The addition of a brief ultrasound examination to clinical assessment increases the ability to confirm placement of double-lumen endotracheal tubes. J Clin Anesth 2010;22(4):246-9.

12. Moritz A, Irouschek A, Birkholz T, et al. The EZblocker for one-lung ventilation in patients undergoing thoracic surgery: clinical applications and experience in 100 cases in a routine clinical setting. J Cardiothorac Surg 2018;13(1):77.

13. Narayanaswamy M, McRae K, Slinger $P$, et al. Choosing a lung isolation device for thoracic surgery: a randomized trial of three bronchial blockers versus double-lumen tubes. Anesth Analg 2009; 108(4):1097-101.

14. Campos JH. Lung isolation techniques for patients with difficult airway. Curr Opin Anaesthesiol 2010; 23(1):12-7.

15. Knoll H, Ziegeler S, Schreiber JU, et al. Airway injuries after one-lung ventilation: a comparison between double-lumen tube and endobronchial blocker: a randomized, prospective, controlled trial. Anesthesiology 2006;105(3):471-7.

16. Honikman R, Rodriguez-Diaz CA, Cohen E. A ballooning crisis: three cases of bronchial blocker malfunction and a review. J Cardiothorac Vasc Anesth 2017;31(5):1799-804.

17. Soto RG, Oleszak SP. Resection of the Arndt bronchial blocker during stapler resection of the left lower lobe. J Cardiothorac Vasc Anesth 2006; 20(1):131-2.

18. Neustein SM. Pro: bronchial blockers should be used routinely for providing one-lung ventilation. J Cardiothorac Vasc Anesth 2015;29(1):234-6.

19. Brodsky JB. Con: a bronchial blocker is not a substitute for a double-lumen endobronchial tube. J Cardiothorac Vasc Anesth 2015;29(1):237-9.

20. Shelley B, Macfie A, Kinsella J. Anesthesia for thoracic surgery: a survey of UK practice. J Cardiothorac Vasc Anesth 2011;25(6):1014-7.

21. Campos JH, Hallam EA, Ueda K. Lung isolation in the morbidly obese patient: a comparison of a leftsided double-lumen tracheal tube with the Arndt(R) wire-guided blocker. Br J Anaesth 2012;109(4): 630-5.

22. Clayton-Smith A, Bennett K, Alston RP, et al. A comparison of the efficacy and adverse effects of double-lumen endobronchial tubes and bronchial blockers in thoracic surgery: a systematic review and meta-analysis of randomized controlled trials. J Cardiothorac Vasc Anesth 2015;29(4): 955-66.

23. Campos $\mathrm{JH}$, Feider A. Hypoxia during one-lung ventilation-a review and update. J Cardiothorac Vasc Anesth 2018;32(5):2330-8.

24. Wang M, Gong Q, Wei W. Estimation of shunt fraction by transesophageal echocardiography during one-lung ventilation. J Clin Monit Comput 2015; 29(2):307-11.

25. Lumb AB, Slinger P. Hypoxic pulmonary vasoconstriction: physiology and anesthetic implications. Anesthesiology 2015;122(4):932-46.

26. Slinger $P$, Suissa S, Triolet W. Predicting arterial oxygenation during one-lung anaesthesia. Can J Anaesth 1992;39(10):1030-5.

27. Wang C, Guo M, Zhang N, et al. Association of body mass index and outcomes following lobectomy for non-small-cell lung cancer. World J Surg Oncol 2018;16(1):90.

28. Bardoczky GI, Szegedi LL, d'Hollander AA, et al. Two-lung and one-lung ventilation in patients with chronic obstructive pulmonary disease: the effects of position and $F(I O) 2$. Anesth Analg 2000;90(1): 35-41.

29. Klingstedt C, Hedenstierna G, Baehrendtz S, et al. Ventilation-perfusion relationships and atelectasis formation in the supine and lateral positions 
during conventional mechanical and differential ventilation. Acta Anaesthesiol Scand 1990;34(6): 421-9.

30. Schwarzkopf K, Schreiber T, Bauer R, et al. The effects of increasing concentrations of isoflurane and desflurane on pulmonary perfusion and systemic oxygenation during one-lung ventilation in pigs. Anesth Analg 2001;93(6):1434-8 [table of contents].

31. Bickler PE, Feiner JR, Lipnick MS, et al. Effects of acute, profound hypoxia on healthy humans: implications for safety of tests evaluating pulse oximetry or tissue oximetry performance. Anesth Analg 2017;124(1):146-53.

32. Grocott MP, Martin DS, Levett DZ, et al. Arterial blood gases and oxygen content in climbers on Mount Everest. N Engl J Med 2009;360(2):140-9.

33. Jouett NP, Watenpaugh DE, Dunlap ME, et al. Interactive effects of hypoxia, hypercapnia and lung volume on sympathetic nerve activity in humans. Exp Physiol 2015;100(9):1018-29.

34. Meyhoff CS, Staehr AK, Rasmussen LS. Rational use of oxygen in medical disease and anesthesia. Curr Opin Anaesthesiol 2012;25(3):363-70.

35. Unzueta C, Tusman G, Suarez-Sipmann F, et al. Alveolar recruitment improves ventilation during thoracic surgery: a randomized controlled trial. $\mathrm{Br}$ J Anaesth 2012;108(3):517-24.

36. Park SH, Jeon YT, Hwang JW, et al. A preemptive alveolar recruitment strategy before one-lung ventilation improves arterial oxygenation in patients undergoing thoracic surgery: a prospective randomised study. Eur J Anaesthesiol 2011;28(4): 298-302.

37. Kim N, Lee SH, Choi KW, et al. Effects of positive end-expiratory pressure on pulmonary oxygenation and biventricular function during one-lung ventilation: a randomized crossover study. J Clin Med 2019;8(5) [pii:E740].

38. Cinnella G, Grasso S, Natale C, et al. Physiological effects of a lung-recruiting strategy applied during one-lung ventilation. Acta Anaesthesiol Scand 2008;52(6):766-75.

39. Tusman G, Bohm SH, Sipmann FS, et al. Lung recruitment improves the efficiency of ventilation and gas exchange during one-lung ventilation anesthesia. Anesth Analg 2004;98(6):1604-9 [table of contents].

40. Slinger PD, Kruger M, McRae K, et al. Relation of the static compliance curve and positive endexpiratory pressure to oxygenation during onelung ventilation. Anesthesiology 2001;95(5): 1096-102.

41. Ferrando C, Mugarra A, Gutierrez A, et al. Setting individualized positive end-expiratory pressure level with a positive end-expiratory pressure decrement trial after a recruitment maneuver improves oxygenation and lung mechanics during one-lung ventilation. Anesth Analg 2014;118(3):657-65.

42. Carraminana A, Ferrando C, Unzueta MC, et al. Rationale and study design for an Individualized Perioperative Open Lung Ventilatory Strategy in Patients on One-Lung Ventilation (iPROVE-OLV). $J$ Cardiothorac Vasc Anesth 2019;33(9): 2492-502.

43. Kiss T, Wittenstein J, Becker C, et al. Protective ventilation with high versus low positive endexpiratory pressure during one-lung ventilation for thoracic surgery (PROTHOR): study protocol for a randomized controlled trial. Trials 2019;20(1):213.

44. El Tahan MR, El Ghoneimy Y, Regal M, et al. Effects of nondependent lung ventilation with continuous positive-pressure ventilation and high-frequency positive-pressure ventilation on right ventricular function during one-lung ventilation. Semin Cardiothorac Vasc Anesth 2010;14(4):291-300.

45. Dikmen Y, Aykac B, Erolcay H. Unilateral high frequency jet ventilation during one-lung ventilation. Eur J Anaesthesiol 1997;14(3):239-43.

46. Kremer R, Aboud W, Haberfeld O, et al. Differential lung ventilation for increased oxygenation during one lung ventilation for video assisted lung surgery. J Cardiothorac Surg 2019;14(1):89.

47. Modolo NS, Modolo MP, Marton MA, et al. Intravenous versus inhalation anaesthesia for one-lung ventilation. Cochrane Database Syst Rev 2013;(7):CD006313.

48. Fradj K, Samain E, Delefosse D, et al. Placebocontrolled study of inhaled nitric oxide to treat hypoxaemia during one-lung ventilation. $\mathrm{Br} J$ Anaesth 1999;82(2):208-12.

49. Dalibon N, Moutafis M, Liu N, et al. Treatment of hypoxemia during one-lung ventilation using intravenous almitrine. Anesth Analg 2004;98(3):590-4 [table of contents].

50. Silva-Costa-Gomes T, Gallart L, Valles J, et al. Lowvs high-dose almitrine combined with nitric oxide to prevent hypoxia during open-chest one-lung ventilation. Br J Anaesth 2005;95(3):410-6.

51. Bermejo S, Gallart L, Silva-Costa-Gomes T, et al. Almitrine fails to improve oxygenation during onelung ventilation with sevoflurane anesthesia. J Cardiothorac Vasc Anesth 2014;28(4):919-24.

52. Schwarzkopf K, Klein U, Schreiber T, et al. Oxygenation during one-lung ventilation: the effects of inhaled nitric oxide and increasing levels of inspired fraction of oxygen. Anesth Analg 2001; 92(4):842-7.

53. Rocca GD, Passariello M, Coccia C, et al. Inhaled nitric oxide administration during one-lung ventilation in patients undergoing thoracic surgery. J Cardiothorac Vasc Anesth 2001;15(2):218-23.

54. Choi H, Jeon J, Huh J, et al. The effects of iloprost on oxygenation during one-lung ventilation for lung 
surgery: a randomized controlled trial. J Clin Med 2019;8(7) [pii:E982].

55. Lee SH, Kim N, Lee CY, et al. Effects of dexmedetomidine on oxygenation and lung mechanics in patients with moderate chronic obstructive pulmonary disease undergoing lung cancer surgery: a randomised double-blinded trial. Eur J Anaesthesiol 2016;33(4):275-82.

56. Huang SQ, Zhang J, Zhang XX, et al. Can dexmedetomidine improve arterial oxygenation and intrapulmonary shunt during one-lung ventilation in adults undergoing thoracic surgery? A metaanalysis of randomized, placebo-controlled trials. Chin Med J (Engl) 2017;130(14):1707-14.

57. Scheeren TWL, Belda FJ, Perel A. The oxygen reserve index (ORI): a new tool to monitor oxygen therapy. J Clin Monit Comput 2018;32(3): 379-89.

58. Alday E, Nieves JM, Planas A. Oxygen reserve index predicts hypoxemia during one-lung ventilation: an observational diagnostic study. J Cardiothorac Vasc Anesth 2020;34(2):417-22.

59. Koishi W, Kumagai M, Ogawa S, et al. Monitoring the oxygen reserve index can contribute to the early detection of deterioration in blood oxygenation during one-lung ventilation. Minerva Anestesiol 2018;84(9):1063-9.

60. Saugel B, Belda FJ. The oxygen reserve index in anesthesiology: a superfluous toy or a tool to individualize oxygen therapy? Minerva Anestesiol 2018;84(9):1010-2.

61. Li XM, Li F, Liu ZK, et al. Investigation of one-lung ventilation postoperative cognitive dysfunction and regional cerebral oxygen saturation relations. J Zhejiang Univ Sci B 2015;16(12):1042-8.

62. Suehiro K, Okutai R. Cerebral desaturation during single-lung ventilation is negatively correlated with preoperative respiratory functions. J Cardiothorac Vasc Anesth 2011;25(1):127-30.

63. Kazan R, Bracco D, Hemmerling TM. Reduced cerebral oxygen saturation measured by absolute cerebral oximetry during thoracic surgery correlates with postoperative complications. $\mathrm{Br} J$ Anaesth 2009;103(6):811-6.

64. Brinkman R, Amadeo RJ, Funk DJ, et al. Cerebral oxygen desaturation during one-lung ventilation: correlation with hemodynamic variables. Can J Anaesth 2013;60(7):660-6.

65. Tang L, Kazan R, Taddei R, et al. Reduced cerebral oxygen saturation during thoracic surgery predicts early postoperative cognitive dysfunction. $\mathrm{Br} \mathrm{J}$ Anaesth 2012;108(4):623-9.

66. Katzenstein AA, Askin FB. Surgical pathology of non-neoplastic lung disease. Major Probl Pathol 1982;13:1-430.

67. Kim HJ, Cha SI, Kim CH, et al. Risk factors of postoperative acute lung injury following lobectomy for nonsmall cell lung cancer. Medicine (Baltimore) 2019;98(13):e15078.

68. Padley SP, Jordan SJ, Goldstraw P, et al. Asymmetric ARDS following pulmonary resection: CT findings initial observations. Radiology 2002; 223(2):468-73.

69. Slutsky AS, Ranieri VM. Ventilator-induced lung injury. N Engl J Med 2014;370(10):980.

70. Jordan S, Mitchell JA, Quinlan GJ, et al. The pathogenesis of lung injury following pulmonary resection. Eur Respir J 2000;15(4):790-9.

71. Schilling T, Kozian A, Huth C, et al. The pulmonary immune effects of mechanical ventilation in patients undergoing thoracic surgery. Anesth Analg 2005;101(4):957-65 [table of contents].

72. Kozian A, Schilling T, Rocken C, et al. Increased alveolar damage after mechanical ventilation in a porcine model of thoracic surgery. J Cardiothorac Vasc Anesth 2010;24(4):617-23.

73. Slinger PD. Do low tidal volumes decrease lung injury during one-lung ventilation? J Cardiothorac Vasc Anesth 2017;31(5):1774-5.

74. Gama de Abreu M, Heintz M, Heller A, et al. Onelung ventilation with high tidal volumes and zero positive end-expiratory pressure is injurious in the isolated rabbit lung model. Anesth Analg 2003; 96(1):220-8 [table of contents].

75. Serpa Neto A, Cardoso SO, Manetta JA, et al. Association between use of lung-protective ventilation with lower tidal volumes and clinical outcomes among patients without acute respiratory distress syndrome: a meta-analysis. JAMA 2012;308(16): 1651-9.

76. Acute Respiratory Distress Syndrome Network, Brower RG, Matthay MA, Morris A, et al. Ventilation with lower tidal volumes as compared with traditional tidal volumes for acute lung injury and the acute respiratory distress syndrome. N Engl J Med 2000;342(18):1301-8.

77. El Tahan MR, Pasin L, Marczin N, et al. Impact of low tidal volumes during one-lung ventilation. A meta-analysis of randomized controlled trials. J Cardiothorac Vasc Anesth 2017;31(5):1767-73.

78. Serpa Neto A, Hemmes SN, Barbas CS, et al. Protective versus conventional ventilation for surgery: a systematic review and individual patient data meta-analysis. Anesthesiology 2015;123(1):66-78.

79. Kidane B, Choi S, Fortin D, et al. Use of lungprotective strategies during one-lung ventilation surgery: a multi-institutional survey. Ann Transl Med 2018;6(13):269.

80. Yang M, Ahn HJ, Kim K, et al. Does a protective ventilation strategy reduce the risk of pulmonary complications after lung cancer surgery?: a randomized controlled trial. Chest 2011;139(3):530-7.

81. Kim KN, Kim DW, Jeong MA, et al. Comparison of pressure-controlled ventilation with volume- 
controlled ventilation during one-lung ventilation: a systematic review and meta-analysis. BMC Anesthesiol 2016;16(1):72.

82. Amato MB, Meade MO, Slutsky AS, et al. Driving pressure and survival in the acute respiratory distress syndrome. N Engl J Med 2015;372(8): 747-55.

83. Park M, Ahn HJ, Kim JA, et al. Driving pressure during thoracic surgery: a randomized clinical trial. Anesthesiology 2019;130(3):385-93.

84. Blank RS, Colquhoun DA, Durieux ME, et al. Management of one-lung ventilation: impact of tidal volume on complications after thoracic surgery. Anesthesiology 2016;124(6):1286-95.

85. McRae K, de Perrot M. Principles and indications of extracorporeal life support in general thoracic surgery. J Thorac Dis 2018;10(Suppl 8):S931-46.

86. Rana M, Yusuff $H$, Zochios V. The right ventricle during selective lung ventilation for thoracic surgery. J Cardiothorac Vasc Anesth 2019;33(7): 2007-16.

87. Al Shehri AM, El-Tahan MR, Al Metwally R, et al. Right ventricular function during one-lung ventilation: effects of pressure-controlled and volumecontrolled ventilation. J Cardiothorac Vasc Anesth 2014;28(4):880-4.

88. Hirsch LJ, Rooney MW, Wat SS, et al. Norepinephrine and phenylephrine effects on right ventricular function in experimental canine pulmonary embolism. Chest 1991;100(3):796-801.

89. Leather HA, Segers P, Berends N, et al. Effects of vasopressin on right ventricular function in an experimental model of acute pulmonary hypertension. Crit Care Med 2002;30(11):2548-52.

90. Ardehali A, Laks H, Levine M, et al. A prospective trial of inhaled nitric oxide in clinical lung transplantation. Transplantation 2001;72(1):112-5.

91. Schwarzkopf K, Schreiber T, Preussler NP, et al. Lung perfusion, shunt fraction, and oxygenation during one-lung ventilation in pigs: the effects of desflurane, isoflurane, and propofol. J Cardiothorac Vasc Anesth 2003;17(1):73-5.

92. Sheybani S, Attar AS, Golshan S, et al. Effect of propofol and isoflurane on gas exchange parameters following one-lung ventilation in thoracic surgery: a double-blinded randomized controlled clinical trial. Electron Physician 2018;10(2): 6346-53.

93. Schilling T, Kozian A, Senturk M, et al. Effects of volatile and intravenous anesthesia on the alveolar and systemic inflammatory response in thoracic surgical patients. Anesthesiology 2011;115(1): 65-74.

94. De Conno E, Steurer MP, Wittlinger M, et al. Anesthetic-induced improvement of the inflammatory response to one-lung ventilation. Anesthesiology 2009;110(6):1316-26.
95. Sun B, Wang J, Bo L, et al. Effects of volatile vs. propofol-based intravenous anesthetics on the alveolar inflammatory responses to one-lung ventilation: a meta-analysis of randomized controlled trials. J Anesth 2015;29(4):570-9.

96. Chappell D, Heindl B, Jacob M, et al. Sevoflurane reduces leukocyte and platelet adhesion after ischemia-reperfusion by protecting the endothelial glycocalyx. Anesthesiology 2011;115(3):483-91.

97. Ng A, Swanevelder J. Hypoxaemia associated with one-lung anaesthesia: new discoveries in ventilation and perfusion. $\mathrm{Br} J$ Anaesth 2011;106(6): 761-3.

98. Ashes CSP. Volume management and resuscitation in thoracic surgery. Curr Anesthesiol Rep 2014;4: 386-96.

99. Zeldin RA, Normandin D, Landtwing D, et al. Postpneumonectomy pulmonary edema. J Thorac Cardiovasc Surg 1984;87(3):359-65.

100. Turnage WS, Lunn JJ. Postpneumonectomy pulmonary edema. A retrospective analysis of associated variables. Chest 1993;103(6):1646-50.

101. Arslantas MK, Kara HV, Tuncer BB, et al. Effect of the amount of intraoperative fluid administration on postoperative pulmonary complications following anatomic lung resections. J Thorac Cardiovasc Surg 2015;149(1):314-20, 321.e1.

102. Casado D, Lopez F, Marti R. Perioperative fluid management and major respiratory complications in patients undergoing esophagectomy. Dis Esophagus 2010;23(7):523-8.

103. Eng OS, Arlow RL, Moore D, et al. Fluid administration and morbidity in transhiatal esophagectomy. J Surg Res 2016;200(1):91-7.

104. Glatz T, Kulemann B, Marjanovic G, et al. Postoperative fluid overload is a risk factor for adverse surgical outcome in patients undergoing esophagectomy for esophageal cancer: a retrospective study in 335 patients. BMC Surg 2017; 17(1):6.

105. Myles PS, Bellomo R, Corcoran T, et al. Restrictive versus liberal fluid therapy for major abdominal surgery. N Engl J Med 2018;378(24):2263-74.

106. Jo JY, Kim WJ, Choi DK, et al. Effect of restrictive fluid therapy with hydroxyethyl starch during esophagectomy on postoperative outcomes: a retrospective cohort study. BMC Surg 2019; 19(1):15.

107. Ahn HJ, Kim JA, Lee AR, et al. The risk of acute kidney injury from fluid restriction and hydroxyethyl starch in thoracic surgery. Anesth Analg 2016; 122(1): 186-93.

108. Batchelor TJP, Rasburn NJ, AbdelnourBerchtold E, et al. Guidelines for enhanced recovery after lung surgery: recommendations of the Enhanced Recovery After Surgery (ERAS(R)) Society and the European Society of Thoracic Surgeons 
(ESTS). Eur J Cardiothorac Surg 2019;55(1): $91-115$.

109. Lee JH, Jeon Y, Bahk JH, et al. Pulse pressure variation as a predictor of fluid responsiveness during one-lung ventilation for lung surgery using thoracotomy: randomised controlled study. Eur J Anaesthesiol 2011;28(1):39-44.

110. Senturk M, Ozcan PE, Talu GK, et al. The effects of three different analgesia techniques on long-term postthoracotomy pain. Anesth Analg 2002;94(1): 11-5 [table of contents].

111. Ozcan PE, Senturk M, Sungur Ulke Z, et al. Effects of thoracic epidural anaesthesia on pulmonary venous admixture and oxygenation during onelung ventilation. Acta Anaesthesiol Scand 2007; 51(8):1117-22.

112. Elmore B, Nguyen V, Blank R, et al. Pain management following thoracic surgery. Thorac Surg Clin 2015;25(4):393-409. 